\title{
ASPECTOS FISIOLÓGICOS DO CAFEEIRO CONILON: UMA ABORDAGEM SISTEMÁTICA
}

\begin{abstract}
BELAN, Leônidas Leoni ${ }^{1}$ SILVA, Kmila Gomes ${ }^{2}$ TOMAZ, Marcelo Antônio ${ }^{3}$ JESUS JUNIOR, Waldir Cintra ${ }^{3}$ AMARAL, José Augusto Teixeira do ${ }^{3}$ AMARAL, José Francisco Teixeira do ${ }^{3}$

RESUMO: As primeiras lavouras comerciais de Café Conilon (Coffea canephora) foram implantadas a partir da década de 50, com o objetivo de cultivarem-se áreas marginais ao Café Arábica (Coffea arabica). Hoje, o conilon representa uma parcela significativa no mercado cafeeiro. Apesar disso, é concenso entre pesquisadores do assunto que os poucos estudos até então desenvolvidos com a cultura se encontra disperso na literatura. Este trabalho teve por objetivo reunir e analisar informações bibliográficas sobre aspectos fisiológicos do cafeeiro conilon, construindo embasamento teórico para pesquisas sobre manejo e condução da lavoura, e até mesmo, direcionar o melhoramento genético da cultura.
\end{abstract}

Palavras chave: Coffea canephora. Fisiologia. Fotossíntese. Produção. Resistência

\section{PHYSIOLOGICAL ASPECTS OF CONILON COFFEE: A SYSTEMATIC APPROACH}

SUMMARY - The first commercial crops Conilon Coffee (Coffea canephora) were implanted from the 50's, aiming to cultivate marginal areas to the Arabica coffee (Coffea arabica). Actually conilon represents a significant portion of the coffee market. Nevertheless, it is consensus among researchers on the subject that few studies have so far developed to culture are scattered in the literature. This study aimed to gather and analyze information literature on physiological aspects of coffee conilon, building theoretical basis for research on management and conduct of the crop, and even direct the coffee breeding.

Keywords: Coffea canephora. Physiology. Photosynthesis. Production. Resistance.

\section{INTRODUÇÃO}

Embora exista um grande número de espécies de café, apenas Coffea arabica L. (café arábica) e Coffea canephora Rerre ex Froefiner (café conilon / robusta) têm importância econômica no mercado mundial. Atualmente, cerca de $71 \%$ da produção brasileira de café é derivada de

\footnotetext{
${ }^{1}$ Eng $^{\circ}$. Agr. Mestrando em Produção Vegetal - PPGPV - CCAUFES - Centro de Ciências Agrárias da Universidade Federal Espírito Santo. Bolsista CAPES. E-mail: leonidas_agronomia@ yahoo.com.br ${ }^{2}$ Bióloga, Mestranda em Ciências Florestais - PPGCF - CCAUFES - Centro de Ciências Agrárias da Universidade Federal Espírito Santo. Bolsista CAPES.

${ }^{3}$ Eng $^{\text {o }}$. Agr. D. Sc. Professor Adjunto Departamento de Produção Vegetal, CCAUFES - Centro de Ciências Agrárias da Universidade Federal do Espírito Santo.
} 
cultivares arábica e o restante, de café robusta. Coffea canephora é cultivada predominantemente nos estados do Espírito Santo, Rondonia, Minas Gerais, Mato Grosso, Bahia e Rio de Janeiro. No Espírito Santo, maior produtor brasileiro da espécie, a producão é originária exclusivamente da variedade Kouillou, popularmente conhecida como Conilon. Essa variedade pertence ao grupo Guineano (BRAGANÇA et al., 2001), apresentando grande variabilidade em relação ao porte, caules ramificados, folhas maduras com comprimento e largura menores que às das demais cultivares da espécie, folhas novas de coloração bronze, frutos vermelhos ou amarelos quando maduros e sementes de tamanhos variados (FAZUOLI, 1986).

As primeiras lavouras comerciais de café conilon foram implantadas a partir da década de 50, com o objetivo de cultivarem-se áreas marginais ao café arábica. A cultura esta presente em 65 dos 78 municípios do Espírito Santo, em uma área aproximada de 290 mil hectares, sendo que na região sul é cultivado principalmente na bacia do rio Itapemirim, e na região norte do Estado os principais produtores são Jaguaré, Sooretama, Vila Valério, São Mateus, Rio Bananal e Pinheiros (FASSIO ; SILVA, 2007).

Apesar de representar uma parcela significativa no mercado cafeeiro, poucos estudos, ao longo do tempo, foram desenvolvidos com a variedade de café Conilon e, portanto, o conhecimento principalmente sobre a fisiologia dessa cultura é ainda muito incipiente se comparado com o café Arábica, e ainda se encontra disperso na literatura (RONCHI ; DaMATTA, 2007). Segundo Melo ; Souza (2010) a primeira etapa no processo de melhoramento de coffea spp. é conhecer os mecanismos que estão envolvidos em sua fisiologia e biologia da reprodução, e a partir de então, traçar os objetivos a serem alcançados com o melhoramento da cultura. No entanto, essas informações se encontram ainda muito dispersas na literatura.

\section{Crescimento Vegetativo}

A periodicidade estacional do crescimento vegetativo do cafeeiro tem sido estudada em várias regiões cafeeiras do mundo, podendo ser muitas as causas para explicar o fenômeno (BARROS ; MAESTRI, 1974; SILVA et al., 2004; AMARAL et al., 2006). Assim como ocorre na grande maioria das regiões produtoras de café do mundo, a taxa de crescimento da parte aérea do cafeeiro (crescimento dos ramos ortotrópicos e plagiotrópicos, formação de nós, expansão foliar etc.) varia sazonalmente, em virtude das condições climáticas, particularmente dos regimes de chuva e de temperatura, apesar do fotoperíodo também ter alguma influência (RONCHI ; DaMATTA, 2007). Segundo Sylvain (1958), o crescimento vegetativo do cafeeiro é complexo, e a periodicidade estacional pode ser atribuída a diversos fatores, tais como a lixiviação de nitrato pelas chuvas, competição dos frutos por fotoassimilados, menor intensidade de luz devido à nebulosidade e baixas temperaturas. 
Nas regiões não-equatoriais, o crescimento da parte aérea geralmente é lento no outono/inverno, durante o período seco e frio e de dias curtos, e rápidos na primavera/verão, coincidindo com o início do período chuvoso e com o aumento das temperaturas e do comprimento do dia (CANNELL, 1976). Com cafeeiros adultos, em condições de campo, as evidências não são conclusivas quanto aos efeitos do fotoperíodo sobre o crescimento das plantas (AMARAL et al., 2006). Tem-se verificado, entretanto, que, em regiões cafeeiras de latitudes mais elevadas, maiores taxas de crescimento coincidem com épocas em que os dias são mais longos (SILVA et al., 2004).

Para o cafeeiro Conilon, especificamente, as poucas informações disponíveis sobre as taxas de crescimento da parte aérea foram obtidas na região de Linhares, norte do Espírito Santo (SILVEIRA, 1996), região onde se concentra grande número de lavouras de café Conilon deste Estado. Em razão da ocorrência frequente de veranicos durante a estação chuvosa e de um período seco relativamente longo, que se estende geralmente de maio a setembro, os cafezais da região nordeste são normalmente cultivados sob irrigação, afetando significativamente o crescimento da parte aérea. Nessa região, em lavouras não-irrigadas, a taxa de crescimento do ramo plagiotrópico é baixa nos meses de junho a setembro $(0,03 \mathrm{~cm}$ dia 1$)$; aumenta com o início das chuvas e atinge valores máximos em outubro $\left(0,40 \mathrm{~cm}\right.$ dia $^{-}$ 1); reduz em dezembro $(0,20 \mathrm{~cm}$ dia 1$)$ e atinge valores mínimos em fevereiro, pelas altas temperaturas; aumenta ligeiramente em março/abril $\left(0,08 \mathrm{~cm}\right.$ dia $\left.{ }^{1}\right)$ e, a partir de maio, retorna aos valores mínimos (SILVEIRA, 1996; SILVEIRA ; CARVALHO, 1996). Portanto, no período seco e de temperaturas mais amenas, as taxas de crescimento são baixas, enquanto no período chuvoso e de temperaturas mais elevadas, porém não extremas, as taxas de crescimento são elevadas. Corroborando esses resultados, em C. arabica, Amaral et al., (2006) verificaram que o crescimento de ramos e da área foliar decresceu a partir de meados de março, atingindo taxas mínimas nos meses de maio e junho, quando foram registradas as menores temperaturas. Destaca-se, nesse caso, o papel importantíssimo das primeiras chuvas após o período seco para o início do crescimento propriamente dito dos ramos plagiotrópicos. E necessário registrar, contudo, que as taxas de crescimento ora apresentadas não são valores fixos, podendo variar, por exemplo, em razão do nível tecnológico e dos tratos culturais empregados em cada lavoura e das variações temporais das condições ambientes, sobretudo as climáticas (RONCHI ; DaMATTA, 2007).

De acordo com Silveira (1996) e Silveira ; Carvalho (1996), lavouras irrigadas continuadamente, por sua vez, o padrão de crescimento dos ramos plagiotrópicos diferenciase consideravelmente daquele de lavouras não-irrigadas. Sob irrigação, a taxa de crescimento dos ramos laterais, que é mínima em julho $(\square 0,03 \mathrm{~cm}$ dia-1), aumenta já em agosto $(\square 0,08 \mathrm{~cm}$ 
dia־4) e setembro (0,17 $\mathrm{cm}$ dia`1), diferentemente da não-irrigada, e atinge taxas máximas em outubro ( $\square 0,33 \mathrm{~cm}$ dia 1 ); a partir desse ponto, as taxas de crescimento assemelham-se àquelas de lavouras não-irrigadas.

No entanto, a manutenção de uma maior área foliar em lavouras irrigadas, em comparação àquela de lavouras não-irrigadas, no final do período seco (SILVEIRA; CARVALHO, 1996), poderia explicar, em parte, as diferenças nas taxas de crescimento dos ramos observadas após o período seco. Em conjunto, esses dados indicam que o atraso de aproximadamente dois meses no restabelecimento do crescimento dos ramos plagiotrópicos em lavouras não-irrigadas, comparadas às irrigadas, pode ser em parte compensado, nas últimas, por uma taxa de crescimento $20 \%$ superior em outubro, mês em que o crescimento é mais intenso. Em outras palavras, apesar de a duração da estação de crescimento de ramos laterais nas lavouras irrigadas ser maior (julho a fevereiro) que nas não-irrigadas (setembro, dependendo das chuvas, a fevereiro), as taxas máximas de crescimento são observadas nas lavouras não-irrigadas. RONCHI ; DaMATTA (2007) concluem que a disponibilidade hídrica, e não a temperatura tem grande importância no restabelecimento do crescimento dos ramos plagiotrópicos após a estação seca.

Em se tratando do aparecimento e expansão de folhas, até o momento, para o cafeeiro Conilon, raros são os estudos investigando qual sua época de ocorrência, taxa de expansão ao longo do ano, tampouco os fatores que a afetam. A produção de folhas no café Conilon, que tem relação direta com a formação de nós nos ramos laterais, provavelmente segue o mesmo padrão de crescimento descrito acima para os ramos plagiotrópicos, ou seja, é intensa na primavera/verão e mínima no outono/inverno (RONCHI ; DaMATTA, 2007).

Amaral et al. (2007) avaliaram o crescimento vegetativo e produtivo de cafeeiros Conilon propagados por estacas em tubetes, e observaram que as maiores taxas de crescimento de ramos e de folhas ocorreram em setembro, novembro e dezembro. Os autores destacam que temperaturas máximas acima de $32{ }^{\circ} \mathrm{C}$ estiveram correlacionadas com quedas acentuadas nas intensidades de crescimento, ocorridas durante a fase de crescimento ativo, na primeira quinzena de outubro e de dezembro, bem como da segunda semana de janeiro até a terceira semana de fevereiro, e na segunda quinzena de março de 2001. Possivelmente, a ocorrência de temperaturas do ar relativamente elevadas expliquem essas quedas no crescimento, porque folhas de café expostas a pleno sol podem apresentar temperaturas de 10 a $15^{\circ} \mathrm{C}$ acima da temperatura do ar (BUTLER, 1977). Nessas condições, essas elevações de temperatura em folhas de café fortemente iluminadas podem ocasionar decréscimos nas taxas fotossintéticas líquidas (NUTMAN, 1937). 
Independentemente da época de formação, a queda de folhas de plantas de café Conilon intensifica-se no final da época seca, coincidindo com o período de colheita/póscolheita e de maior ação dos ventos, e é afetada fortemente pela irrigação, conforme observado por Silveira (1996) e Silveira e Carvalho (1996). Esses autores verificaram reduções de aproximadamente $60 \%$ no número de folhas por nó, no período de maio a setembro, em lavouras não-irrigadas, e de apenas 33\%, durante o mesmo período, em lavouras irrigadas. Além disso, constataram maior longevidade foliar na lavoura irrigada.

O crescimento do cafeeiro Conilon (planta inteira) foi avaliado por Bragança (2005), com base na produção de massa seca total ao longo de seis anos, em lavoura formada a partir da variedade clonal Emcapa 8111 (clone 02) e conduzida em livre crescimento, em Marilândia/ES. Os resultados obtidos resultados sugerem que, com o envelhecimento da lavoura, estabelece-se gradualmente um desequilíbrio entre a área foliar (associada à fotossíntese) e a massa seca total da planta, que passa a ser constituída basicamente pelo excesso de ramos ortotrópicos, que se tornam fortes drenos por fotoassimilados. Como não há crescimento compensatório, principalmente em área foliar, o vigor das lavouras se reduz gradualmente e, da mesma forma, a produtividade. Tomadas em conjunto, essas informações indicam, de forma contundente, a importância e a necessidade de realização da poda na lavoura de café conilon. (BRAGANÇA, 2005).

\section{Sistema Radicular}

Segundo Ronchi e DaMatta (2007) informações sobre o crescimento de raízes do café Conilon são bem mais escassas que as disponíveis para o café Arábica.

O sistema radicular do café Conilon concentra-se na projeção de sua copa, nas proximidades do tronco, e sua estrutura e distribuição no solo são muito semelhantes àquelas do café Arábica (RENA ; DaMATTA, 2002). Apesar de existirem relatos na literatura de que a maior robustez do café robusta esteja associada à maior extensão e eficiência de seu sistema radicular, tanto na absorção de água como de nutrientes, a distribuição, a arquitetura e a profundidade das raízes podem ser afetadas por diversos fatores edáficos, como textura, estrutura, profundidade, densidade aparente e fertilidade, como também por outros fatores, como regime hídrico, tipo de irrigação, densidade de plantio, localização de adubos, genótipos, dentre outros (RENA ; DaMATTA, 2002).

Partelli et al. (2006) compararam o desenvolvimento de plantas de café Conilon propagadas por sementes ou via propagação vegetativa (estacas). Segundo os autores, foi verificada diferença no diâmetro médio das raízes laterais, das plantas propagadas por 
sementes e por estacas, de 0,355 mm e 0,336 mm, respectivamente, no entanto, não há diferença no comprimento e na área superficial de raízes finas por volume de solo.

A irrigação afeta o padrão de crescimento radicular, reduzindo a profundidade de penetração da raiz pseudo-pivotante e estimulando o desenvolvimento de raízes primárias e secundárias nas camadas mais superficiais do solo (RENA, 1998). Estudos realizados por Bragança (2005) reforçam as hipóteses de que em anos de carga elevada há o esgotamento da planta e o consequente comprometimento do sistema radicular, e que há crescimento do sistema radicular durante o inverno, principalmente em lavoura irrigada. $\mathrm{O}$ aumento da densidade de plantio, por sua vez, favorece o aprofundamento do sistema radicular, melhorando o aproveitamento da água disponível (RENA, 1998).

Outro fator que pode afetar a qualidade do sistema radicular do café conilon e que, no passado, constituiu-se em grandes problemas da cafeicultura capixaba, é a formação de mudas a partir de estacas (clones) mantidas por longos períodos em tubetes. Nesse caso, verificam-se raízes mal formadas e raquíticas, que quando levadas ao campo, tornam-se enoveladas, superficiais e deformadas, resultando na redução da absorção de água e nutrientes e na morte de plantas, principalmente em anos de carga intensa (RENA, 1998). No entanto, Amaral et al, (2007) avaliaram o crescimento vegetativo e a produtividade de cafeeiros conilon oriundos de mudas produzidas por estacas plantadas inicialmente em tubetes plásticos de $50 \mathrm{~cm}^{3}$ de capacidade, por períodos de permanência nos tubetes de 15, 30, 45 e 60 dias, e sucessivamente transplantadas para sacos de polietileno, contendo mistura de terra, esterco de curral e adubo químico, enviveiradas e posteriormente plantadas em condições de campo, na área experimental do Centro das Ciências Agrárias da Universidade Federal do Espírito Santo (CCAUFES) em Alegre, Sul do Estado do Espírito Santo. Segundo esses autores, a produção inicial de mudas de café Conilon em tubetes não afetou o crescimento vegetativo, tampouco a produção de frutos.

Nos períodos secos e frios (inverno) ou secos e quentes (veranicos) o crescimento da parte aérea do cafeeiro Conilon é reduzido. Entretanto, durante esse período, acredita-se que o crescimento das raízes, principalmente daquelas de menor diâmetro e mais profundas, não cessa (RENA, 1998).

O volume e a quantidade de matéria seca de raízes de café conilon variam conforme o clone utilizado (PINHEIRO et al., 2005).

\section{Crescimento Reprodutivo}

\section{- Floração}

O café é uma espécie tropical de hábito gregario, ou seja, todas as plantas de uma 
certa extensão geográfica florescem simultaneamente (RENA ; BARROS, 2004). Todavia, um número variável de floradas com imensidades e temporalidades variáveis são, geralmente, observadas em campo. Em café conilon, as inflorescências (glomérulos) são formadas a partir de gemas seriadas (sendo um glomérulo por cada gema) localizadas aleatoriamente nas axilas das folhas de ramos laterais que se formaram na estação de crescimento do ano corrente, de forma que a floração depende estreitamente do crescimento dos ramos plagiotrópicos (MOENS, 1968; BARROS et al., 1978).

Segundo Rena ; Barros (2004), esse processo complexo pode ser dividido em quatro fases: (î) iniciação, (ii) diferenciação, (iii) período de dormência do botão floral e (iv) abertura da flor ou florada. Para o café conilon, particularmente, os eventos associados às fases iniciais da floração são totalmente desconhecidos. Na literatura, há menção a apenas um trabalho, realizado há quatro décadas, em que se estudou a morfogênese ou morfologia de gemas, porém de Coffea canephora cv. Robusta (MOENS, 1968). Verificou-se que o primórdio floral com altura inferior a $0,3 \mathrm{~mm}$ ainda não havia sofrido diferenciação, que ocorreu somente quando o ápice cônico e proeminente do meristema tornou-se largo e achatado. Externamente, a olho nu, a constatação de estipulas completamente comprimidas ao ramo lateral e de que o nó não mostra qualquer alargamento acima delas indica que a gema floral ainda não está diferenciada (MOENS, 1968; BARROS et al., 1978).

Os botões florais, após passarem por um período de dormência, tornam-se sensíveis ou "maduros" e reagem aos estímulos externos desencadeadores de um rápido crescimento, que dura cerca de 10 dias, levando à abertura das flores. Em condições naturais, a florada em café é provocada pelas primeiras chuvas da estação após um período de seca (RENA et al., 2001), que ocorre, geralmente, em lavouras de conilon não-irrigadas do Espírito Santo, em agosto/setembro. É importante ressaltar, entretanto, que informações acerca dos fatores (luz, temperatura, disponibilidade hídrica, chuvas, relação carbono/nitrogénio, níveis de carboidratos, carga de frutos, hormônios) que supostamente regulam as diferentes fases da floração, assim como os eventos de natureza bioquímica, fisiológica e morfológica, que ocorrem na gema durante sua diferenciação, dormência e nos momentos que antecedem a florada, são praticamente desconhecidos em café Conilon (RONCHI ; DaMATTA, 2007).

O desenvolvimento do botão floral em café conilon, do período final de dormência até a antese, foi estudado em Linhares, em lavouras conduzidas com e sem irrigação. Nesse caso, foram definidos quatro estádios de desenvolvimento de botões florais; achatado, ovalado de coloraçlo verde, ovalado de coloração verde-clara e flor propriamente dita. Verificou-se que a irrigação atrasou o desenvolvimento do botão floral em relação àquele observado em lavouras não-irrigadas (SILVEIRA ; CARVALHO, 1996). 
Silveira; Carvalho (1996) constataram que, apesar do maior número de glomérulos por axila foliar, as plantas irrigadas apresentaram menor número de flores por glomérulo que as plantas não-irrigadas. Tomados em conjunto, esses dados sugerem, a exemplo do que ocorre com o café arábica, que um período seco pode contribuir para a maturação mais concentrada e antecipada dos botões florais de café Conilon, com a concentração, no tempo, da florada (BARROS et al., 1978; RENA et al., 2001; DaMATTA, 2004). No entanto, ainda não se sabe quanto, quando e a intensidade desse défcit hídrico, além dos seus possíveis efeitos colaterais às plantas.

Notadamente dois estádios reprodutivos do café podem ser prejudicados com a ocorrência de estiagens: a floração e a granacão dos frutos. No primeiro, a ocorrência de estiagem apos a florada faz com que haja menor pegamento dos frutos. Já na granacão, a ocorrência de estiagem faz com que aumente a presença de frutos chochos e/ou mal granados. Alem desses dois estádios, o crescimento vegetativo do cafeeiro também pode ser prejudicado pela estiagem (DAMATTA et al., 2007; PEZZOPANE et al., 2010).

\section{- Frutificação}

Após a abertura das flores, inicia-se a fase de frutificação do cafeeiro, na qual ocorre o pegamento, o desenvolvimento e a maturação dos frutos. O pegamento final de frutos de café conilon, avaliado como a percentagem de frutos de café presentes nos ramos após a florada em relação ao número inicial de flores, foi de aproximadamente $30 \%$ para plantas não-irrigadas ou irrigadas continuamente, sendo que a maior taxa de queda de frutos ocorreu no final da fase chumbinho e, principalmente, durante a fase de expansão rápida dos frutos (SILVEIRA ; CARVALHO, 1996).

Em café robusta existem divergências quanto ao tipo de curva utilizado para caracterizar o crescimento de frutos, nos poucos trabalhos publicados com essa espécie no mundo (SRINIVASAN et al., 1978), apesar de Rena et al. (2001) sugerirem que o padrão sigmoidal seja comum a ambas as espécies, café arábica e robusta. Especificamente para o café conilon no Brasil, Silveira (1996) sugeriu que o crescimento de frutos, com base no acúmulo de massa seca, seguiu o modelo sigmoidal duplo, quando cultivado sem irrigação, e o sigmoidal simples, quando irrigado.

Atualmente, a grande maioria das lavouras de café Conilon é formada por variedades clonais, sendo cada variedade composta por um determinado número de clones. É importante ressaltar, entretanto, que a florada desses clones ocorre, na mesma época, em agosto/setembro, por ocasião das "chuvas de florada" (RONCHI ; DaMATTA, 2007). Contudo, o período posterior, da abertura da flor à completa maturação (colheita), é diferenciado para cada clone: clone precoce - 34 semanas (colheita em maio), clone intermediário - 41 semanas (colheita em junho), clone tardio - 
45 semanas (colheita em julho) (BRAGANÇA et al., 1993). Isso indica que há padrões diferenciados de crescimento e maturação de frutos entre clones de café Conilon.

Bragança et al. ( 2001) selecionaram e multiplicaram clones de café Conilon para obtenção de variedades clonais mais produtivas e de melhor qualidade. Alguns clones foram selecionados, agrupadas e lançadas as variedades clonais EMCAPA 8111, EMCAPA 8121 e EMCAPA 8131 que apresentam ciclo de maturação precoce, médio e tardio, respectivamente, sendo que a obtenção de variedades clonais, com ciclo diferenciado de maturação dos frutos, melhora a qualidade do café no Estado do Espírito Santo.

Ronchi; DaMatta (2007) avaliando o desenvolvimento de frutos de café Conilon provenientes de clones precoces apresentam uma escala visual das fases de desenvolvimento dos frutos até a $36^{\mathrm{a}}$ semana após a florada.

Externamente, na grande maioria dos clones de café conilon, o pericarpo passa de verde a vermelho. Com base nessa alteração de cor, facilmente identificável em nível de campo, Ronchi ; DaMatta (2007) propõem uma escala visual para avaliação da maturação do fruto do café conilon, principalmente dos gennoplasmas que apresentam coloração vermelha característica quando maduro.

Em se tratando dos efeitos do sombreamento na maturação dos frutos de café Conilon, constatou-se que frutos de um determinado clone cultivado a pleno sol apresentavam-se no estádio de maturação 2 (verde-amarelado) segundo a escala proposta por Ronchi ; DaMatta (2007), enquanto frutas desse mesmo clone sob sombreamento apresentavam-se ainda no estádio 1 (verde), numa mesma época de avaliação (RONCHI et al., resultados não apresentados). Silveira ; Carvalho (1996) avaliaram o efeito da irrigação na maturação do fruto do cafeeiro conilon e verificaram, adotando-se o critério de contagem do número de plantas com frutos completamente maduros, que a irrigação durante o ano todo atrasou a maturação dos frutos em 15 dias, se comparada à da lavoura não-irrigada.

\section{Relações Hídricas, Movimento Estomático e Transpiração}

Estudos conduzidos no Espírito Santo têm mostrado grande diversidade genética entre clones de Conilon, quanto à produção sob condições de seca. Nessas condições, observam-se clones sensíveis à seca, com baixo vigor, desfolha considerável e grande comprometimento da produção e clones que exibem bom vigor e produtividades médias praticamente inalteradas (SILVA et al., 2010).

As folhas do cafeeiro mantêm um elevado teor relativo de água, mesmo a potenciais hídricos consideravelmente negativos (DaMATTA et al., 2002; PINHEIRO et al., 2005), provavelmente um meio das plantas de café Conilon evitar, em vez de tolerar, a dessecação 
(DaMATTA et al., 1993). Portanto, sintomas visíveis de murcha na folhagem são raros, a menos que a umidade do solo esteja extremamente baixa. $\mathrm{O}$ alto teor relativo de água no ponto de perda de turgescência, usualmente próximo a 90\%, parece estar largamente associado à alta rigidez da parede celular. Nesse ponto, os potenciais hídricos situam-se na faixa de -1,7 a -2,2 MPa em clones de café conilon irrigados, com valores mais negativos para clones não-irrigados, exibindo algum grau de ajustamento osmótico (aumento líquido na concentração de solutos do suco celular), conforme sumariado por DaMatta; Ramalho (2006).

Os principais mecanismos fisiológicos de tolerância diferencial à seca entre clones de Conilon são governados pela eficiência de extração da água do solo e pelas taxas de uso da água pelas plantas (DaMATTA ; RAMALHO, 2006). Avaliações fisiológicas sugerem que clones com produção relativamente elevada em condições de seca são capazes de manter potenciais hídricos foliares adequados, por meio da combinação do aprofundamento do sistema radicular e aumento no controle estomático (SILVA et al., 2010).

Algumas características bioquímicas também são importantes para o aumento da tolerância ao estresse hídrico, entre elas, a manutenção da capacidade de transporte de fotoassimilados da parte aérea para as raízes, que pode permitir maior crescimento radicular e, dessa forma, maior acesso a horizontes mais profundos do solo, de modo a aumentar a absorção de água (SILVA et al., 2010).

Estudos afirmam que o café Conilon apresenta maior densidade estomática, mas com estômatos menores que o café Arábica, sendo que em coffea canephora os estômatos predominantemente são do tipo actinocítico (CARVALHO et al., 2001). Em ambas as espécies, o fechamento estomático tem sido frequentemente considerado como o indicador primário do déficit hídrico (DaMATTA, 2004). Pinheiro et al. (2005) demonstraram que a condutância estomática decresce curvilinearmente com a redução da disponibilidade hídrica, sugerindo alta sensibilidade estomática ao desenvolvimento de déficits hídricos na planta de café conilon. No entanto, esses autores observaram rápida recuperação (1-2 dias) da hidratação foliar e da condutância estomática, que alcançaram valores típicos de cafeeiros irrigados continuamente, após re-irrigarem clones de conilon severamente desidratados. Tal comportamento parece ser de grande importância na determinação do rápido restabelecimento do crescimento e desenvolvimento da copa do café após períodos prolongados de seca, e atesta um alto grau de tolerância à seca ao café Conilon (DaMATTA ; RAMALHO, 2006).

O estômato do café Conilon pode responder às variações na demanda evaporativa da atmosfera independentemente do status hídrico foliar (PINHEIRO et al., 2005). De modo geral, clones de conilon mostram alta sensibilidade estomática à demanda evaporativa, mas aparentemente menor que a das cultivares de Arábica (DaMATTA, 2004; DaMATTA ; 
RAMALHO, 2006). Isso pode explicar, pelo menos em parte, o porquê de genótipos de Conilon responderem melhor à irrigação que os de Arábica (DaMATTA, 2004). No entanto, verifica-se maior sensibilidade estomática à demanda evaporativa do ar em arábica (RONCHI ; DaMATTA, 2007).

A resposta direta do estômato a variações na umidade relativa tem consequências importantes no que respeita à capacidade da planta de suportar períodos relativamente longos de déficit hídrico no solo associados a condições de alta demanda evaporativa na atmosfera. Sob tais condições, o rápido fechamento do estômato seria vantajoso para o cafeeiro, visto que isso resultaria em diminuição substancial da transpiração. Por outro lado, sob disponibilidade hídrica adequada ou sob períodos curtos de déficit hídrico, a sensibilidade do estômato à umidade do ar seria desvantajosa. Nessas condições, a maximização da absorção do $\mathrm{CO}_{2}$ para a fotossíntese passaria a ter maior importância que a redução da transpiração, em termos de manutenção da produtividade, sob condições de seca (DaMATTA, 2003).

Pinheiro et al. (2005) salienta que há clones de Conilon que pouco respondem às variações da demanda evaporativa e, por essa razão, sofrem desidratação relativamente rápida em períodos de estiagem, o que concorre para uma baixa tolerância à seca. Por sua vez, clones sensíveis ao déficit hídrico possuem um controle deficiente da transpiração, com os estômatos respondendo de forma limitada à redução da disponibilidade de água do solo, e também possuem uma baixa capacidade de absorção de água, pois têm sistemas radiculares mais superficiais (RONCHI ; DaMATTA, 2007). Com o objetivo de identificar e compreender os mecanismos fisiológicos de tolerância ao déficit hídrico em café, DaMatta et al. (2003) selecionaram no Estado do Espírito Santo, clones com tolerâncias contrastantes ao déficit hídrico.

Segundo Ronchi ; DaMatta (2007) sinais radiculares (possivelmente ácido abscísico) estariam envolvidos no controle das trocas gasosas da parte aérea do cafeeiro Conilon.

\section{Fotossíntese e Produtividade}

As taxas de fotossíntese líquida do café Conilon são relativamente baixas (DaMATTA, 2003, 2007; PINHEIRO et al., 2005). Isso indica que o Conilon, assim como as cultivares de café Arábica, exibe baixa eficiência fotossintética em relação à da maioria das plantas lenhosas (CANNELL, 1985). Pouco se sabe sobre os mecanismos que explicariam a magnitude das taxas fotossintéticas do cafeeiro, mas, aparentemente, uma alta resistência à difusão do $\mathrm{CO}_{2}$, desde a atmosfera até o cloroplasto, parece ter papel preponderante nessa resposta (DaMATTA et al., 2001, 2007).

A comparação entre os vários resultados disponíveis na literatura permite inferir que as cultivares de café arábica e clones de conilon exibem taxas máximas de fotossíntese líquida 
similares. No entanto, em face da provável maior sensibilidade estomática à demanda evaporativa do ar em Arábica do que em Conilon, é lícito sugerir que o último possa manter, ao longo do dia, maior absorção cumulativa de $\mathrm{CO}_{2} \mathrm{e}$, por conseguinte, maiores taxas globais de fotossíntese, o que poderia refletir-se na maior produção de frutos em Conilon que em Arábica, conforme frequentemente observado (RONCHI ; DaMATTA, 2007; DaMATTA, 2007).

Campostrini e Maestri (1998) concluíram que as diferenças de produtividades de cinco clones de conilon não estiveram associadas a diferenças na capacidade fotossintética ou no rendimento quântico de folhas isoladas, tampouco com diferenças na concentração de pigmentos cloroplastídicos ou características morfológicas da folhagem. Resultados de DaMatta et al. (2000) também sugerem que diferenças clonais de produtividade não devem estar associadas com potenciais variações nas taxas de fotossíntese líquida de folhas isoladas. Segundo esses autores, provavelmente diferenças de produtividade estariam associadas mais diretamente com a manutenção de uma área foliar sadia (maiores taxas de fotossíntese da planta inteira, ao longo do tempo) e com uma arquitetura de copa mais favorável à maximização das trocas gasosas.

No cafeeiro, como na maioria das plantas C3 a fotossíntese é saturada a cerca de 1/3 da irradiância máxima incidente sobre a copa, i.e, cerca de 600-700 mmol (fótons) $\mathrm{m}^{2} \mathrm{~s}^{-1} \mathrm{em}$ folhas expostas (DaMATTA ; MAESTRI, 1997). A irradiância excedente absorvida pela folha, se não dissipada satisfatoriamente, faz com que a planta perca o controle do metabolismo das espécies reativas de oxigênio, levando à ocorrência de danos fotooxidativos (DaMATTA ; RAMALHO, 2006), popularmente conhecidos como escaldadura. Esses danos se manifestam pelo aparecimento de áreas cloróticas, que evoluem para a necrose, levando, pois, à abscisão foliar.

A pleno sol, cafeeiros bem adubados e irrigados devem dissipar satisfatoriamente o excesso de energia radiante que recebem e, portanto, a escaldadura, caso ocorrente, deve afetar apenas marginalmente a produção do cafezal. Isso explicaria, pelo menos em parte, o sucesso do cultivo de Conilon, como também das cultivares Arábicas a pleno sol (DaMATTA ; MAESTRI, 1997; DaMATTA, 2007), ainda que as espécies sejam originalmente de ambientes sombreados. Por outro lado, sob certas condições, os mecanismos de defesa da planta podem não ser suficientes para dissipar a energia excedente e, nesse caso, a ocorrência de escaldadura pode ser bastante expressiva. Dentre tais condições, destacam-se: cafezais mal-adubados, carga pesada de frutos, déficit hídrico e extremos de temperatura, ou qualquer outro fator que leve ao depauperamento da planta. Nessas condições, a incidência de bicho-mineiro, cercosporiose e ferrugem usualmente aumenta, também levando à abscisão foliar (RONCHI ; DaMATTA, 2007).

Lima et al. (2002) avaliando dois clones de café Conilon sob condições de seca, observaram aumentos na atividade do sistema antioxidante do clone tolerante à seca que no clone 
sensível à seca. Os autores propuseram que a tolerância à seca no Conilon poderia, pelo menos em parte, estar associada a um incremento da atividade do sistema antioxidante.

\section{Tolerância a Seca}

Em suma, os principais componentes da adaptação diferencial à seca entre clones de conilon parecem ser comportamentais, sendo provavelmente governados pelas taxas de uso da água e/ou pela eficiência de extração da água do solo (DaMATTA et al., 2000; 2003; PINHEIRO et al., 2005; DaMATTA ; RAMALHO, 2006). Avaliações fisiológicas sugerem que clones com produção relativamente elevada sob seca o fazem via manutenção de status hídrico adequado (via combinação de sistemas radiculares profundos e controle estomático satisfatório da transpiração) e manutenção da área foliar com folhas com orientação mais verticalizada; além disso, características bioquímicas seriam também importantes, como a existência de sistema antioxidativo mais robusto e manutenção da capacidade de exportação (o que permitiria, por exemplo, o crescimento radicular e, assim, maior acesso a horizontes mais profundos do solo, de modo a aumentar a absorção de água (RONCHI ; DaMATTA, 2007).

Como um todo, essas informações sugerem que não há uma característica isolada capaz de predizer adequadamente a tolerância à seca do conilon em termos de manutenção da produção em ambientes sujeitos à restrição hídrica (DaMATTA ; RAMALHO, 2006).

MORFOFISIOLOGIA: $C$. arabica vs. C. canephora

Carvalho et al. 2001 realizaram um estudo tendo como objetivo comparar cafeeiros das espécies Coffea arabica cv. Catuaí-Vermelho e C. canephora cv. Conilon quanto à fotossíntese líquida e a aspectos da anatomia foliar a esta relacionados. Alguns dos resultados obtidos por esses autores foram:

- Maiores taxas de condutância estomática, transpiratória e fotossintética das plantas de Conilon;

- A temperatura foliar interna não diferiu estatisticamente entre as duas cultivares;

- Os cafeeiros da cultivar Catuaí Vermelho apresentaram maiores médias de emissão de fluorescência do que os cafeeiros Conilon;

- As folhas do cafeeiro C. canephora cv. Conilon apresentam maior eficiência do sistema antena, para a absorção e transferência de energia luminosa do que os cafeeiros de C. arabica cv. Catuaí-Vermelho;

- A forma e disposição das folhas das duas cultivares são similares: ambas apresentam folhas opostas, cruzadas, curto-pecioladas, com lâminas elípticas a elíptico-lanceoladas e margens onduladas. 
- As folhas dos cafeeiros Conilon, no estádio de desenvolvimento estudado, são maiores, apresentando maior área superficial para captação de luz.

- Cortes transversais às lâminas foliares das duas cultivares evidenciaram a maior espessura das folhas de Catuaí Vermelho;

- Em café arábica os estômatos são predominantemente do tipo paracítico, enquanto no conilon predomina o tipo actinocítico;

- As plantas de Conilon, além disso, apresentam maiores valores de índice estomático, e estômatos menores.

\section{REFERÊNCIAS}

AMARAL, J.A.T.do et al. Crescimento vegetativo e produtividade de cafeeiros conilon propagados por estacas em tubetes. Ciência e Agrotecnologia, Lavras, v. 31, n. 6, p. 16241629, 2007.

AMARAL; J.A.T. do; RENA, A,B.; AMARAL. J.F.T. do. Crescimento vegetativo sazonal do cafeeiro e sua relação com fotoperíodo, frutificação, resistência estomática e fotossíntese.

Pesquisa Agropecuária Brasileira, Brasília, v.41, n.3, p.377-384, 2006.

BARROS, R.S.; MAESTRI, M.; COONS, M.P The physiology of flowering in coffee: a review. Journal of Coffee Research, v. 8, p. 29-73, 1978.

BARROS, R.S.; MAESTRI, M. Influência dos fatores climáticos sobre a periodicidade de crescimento vegetativo do café (Coffea arabica L.). Revista Ceres, v.21, p.268-279, 1974.

BRAGANÇA, S.M. Crescimento e acúmulo de nutrientes pelo cafeeiro conilon (Coffea canephora Pierre). 2005. 99 f. Tese (Doutorado em Fitotecnia) - Universidade Federal de Viçosa.

BRAGANÇA, S.M. et al. 'Emcapa 8111', 'Emtapa 8121', 'Emcapa 8131': primeiras variedades clonais de café conilon lançadas para o Espírito Santo. Vitória, ES: Emcapa -.1993. 2 p. (Comunicado Técnico 68).

BRAGANÇA, S.M.et al. Variedades clonais de café Conilon para o Estado do Espírito Santo. Pesquisa Agropecuária Brasileira, v. 36, n. 05, p. 765-770, 2001.

BUTLER, D.R. Coffee leaf temperatures in a tropical environment. Acta Botanica Neerlandica, Amsterdam, v. 26, n. 2, p. 129-140, 1977.

CAMPOSTRINI, E.; MAESTRI, M. Photosyneetic potentkl of five genotypes oí Coffea amephora Pierre. Revista Brasileira de Fisiologia Vegetal, v. 10, p. 13-18, 1998.

CANNELL, M.G.R. Crop physiological aspects of coffee bean yield - a review. Kenya Coffee, v. 41, p. 245-253, 1976.

CANNELL, M.G.R. Physiology of coffee crop. In: CLIFFORD, M.N.; WILLSON, K. C. (Eds,)- Coffee: botany, biochemistry and production of beans and beverage. London, Croom Helm, p. 108-134, 1985. 
CARVALHO, L.M.C.et al. Aspectos morfofisiológicos das cultivares de cafeeiro Catuaí Vermelho e Conilon. Pesquisa Agropecuária Brasileira, Brasília, DF: v.36, p.411-416, 2001.

DaMATTA, E.M. Ecophysiological constraints on the production of shaded and unshaded coffee: a review. Field Crops Research, v. 86, p. 99-114, 2004.

DaMATTA, E M.; MAESTRI, M. Photoinhibition and recovery of photosynthesis in Coffea arabka and C. canepkora. Photosynthetka, v. 34, p. 439-446, 1997.

DaMATTA, E.Met al. Water relations of coffee leaves (Coffea arabica and C. canephora) in response to drought. Journal of Horticttltural Scienee, v. 68, p. 741-746, 1993.

DaMATTA, F.M.; RENA, A.B. Ecofisiologia de cafezais sombreados e a pleno Sol. In: ZAMBOLIM, L. (Ed.). O estado da arte de tecnologias na produção de café. Viçosa, MG: Universidade Federal de Viçosa, 2002, p. 93-135.

DAMATTA, F.M.et al. Ecophysiology of coffee growth and production. Brazilian Journal of Plant Physiology. v.19, n.4, p.485-510. 2007.

DaMATTA, F.M.; LOOS, R.A.; RODRIGUES, R.; BARROS, R.S. Actual and potential photosynthetic rates of tropical crop species. Brazilian Journal of Plant Physiology, v.13, p. 24-32, 2001.

DaMATTA, F.M.; RAMALHO, J.D.C. Impacts of drought and temperature stress on coffee physiology and production: a review. Brazilian Journal of Plant Physiology, v. 18, p. 55-81, 2006.

DaMATTA, F.M.et al. Eficiência do uso da água e tolerância à seca em Coffea canephora. In: SIMPÓSIO DE PESQUISA DOS CAFÉS DO BRASIL, 1., 2000, Poços de Caldas, MG. Anais... Brasília: Embrapa Café, 2000, p. 907-910.

DAMATTA, F.M.et al. Drought tolerance of two field-grown clones of Coffea canephora.

Plant Science, v.164, p.111-117, 2003.

FASSIO, L.H.; SILVA, A.E.S. da. Importância econômica e social do cafe Conilon. In: FERRÃO, R.G.et al. (Ed.). Café Conilon. Vitória, ES: Incaper, 2007, p. 37-52.

FAZUOLI, L.C. Genética e melhoramento do cafeeiro. In: RENA, A. B.et al. (Eds.). Cultura do Cafeeiro: fatores que afetam a produtividade. Piracicaba: POTAFOS, 1986, p. 87-114.

LIMA, A.L.; DaMATTA, E.M.; PINHEIRO, H.A.; TOTOLA, M.R.; LOUREIRO, M.E. Photochcmical responses and oxidative stress in two clones of Coffea canephora under water déficit conditions. Environmental and Experimental Botany, v.47, p. 239-247, 2002.

MELO, B. de; SOUZA, L.B.de. Biologia da reprodução de Coffea arabica L. e Coffea canephora Pierre. Revista Verde de Agroecologia e Desenvolvimento Sustentável, Mossoró-RN, v.5, n.3, p. 05-11 2010.

MOENS, P. Investigaciones morfológicas, ecológicas y fisiológicas sobre cafetos. Turrialba, San Jose, v.18, n.3, p.209- 233, 1968.

NUTMAN, F.J. Studies of the physiology of Coffea arabica: I. photosynthesis of coffee leaves under natural conditions. Annals of Botany... Oxford, v. 1, n. 3, p. 353-367, July 1937. 
PARTELLI, F.L.; VIEIRA, H.D.; SANTIAGO, A.R.; BARROSO, D.G. Produção e desenvolvimento radicular de plantas de café 'Conilon' propagadas por sementes e por estacas. Pesquisa Agropecuária Brasileira. v.41, n.6, p.949-954. 2006.

PEZZOPANE, J.R.M.et al. Zoneamento de risco climático para a cultura do café Conilon no Estado do Espírito Santo. Ciência Agronômica, v. 41, n. 3, p.341-348, 2010.

PINHEIRO, H.A.et al. Drought tolerance is associated with rooting depth and stomatal control of water use in clones aí Coffea canephora. Annals of Botany... v.96, p. 101-108, 2005.

RENA, A.B.; DAMATTA, F.M. O sistema radicular do cafeeiro: morfologia e ecofisiologia. In: ZAMBOLIM, L. (Ed.). O estado da arte de tecnhgas na produção de café. p. 11-92, 2002.

RENA, A.B. A água na fisiologia do cafeeiro., In: SIMPÓSIO ESTADUAL DO CAFÉ, 1998, Vitória. Anais... Vitória: CETCAF, 1998, p. 132-152.

RENA, A.B.; BARROS, R.S. Aspectos críticos no estudo da floração do café. In: ZAMBOLIM, L. (Ed.). Efeitos da irrigação sobre a qualidade e produtividade do café, p. 149172, 2004.

RENA, A.B.; BARROS, R.S.; MAESTRI, M. Desenvolvimento reprodutivo do cafeeiro. In: ZAMBOLIM, L. (Ed.). Tecnologas de produção de café com qualidade. 2001, p. 101-128.

RONCHI, C.P.; DaMATTA, F.M. Aspectos fisiológicos do Café Conilon. In: FERRÃO, R. G.; FONSECA, A.F.A.et al. (Ed.). Café Conilon. Vitória, ES: Incaper, 2007, p. 95-119.

SILVA, E.A.et al. Seasonal changes in vegetative growth and photosynthesis of Arabica coffee trees. Field Crops Research, v.89, p.349-357, 2004.

SILVA, V.A.et al. Resposta fisiológica de clone de café Conilon sensível à deficiência hídrica enxertado em porta-enxerto tolerante. Pesquisa Agropecuária Brasileira, Brasília, v.45, n.5, p.457-464, 2010.

SILVEIRA, J.S.M.; CARVALHO, C.H.S. de. Efeito da época de irrigação sobre o crescimento do ramo plagiotrópico e da longevidade foliar do café conilon. In: CONGRESSO BRASILEIRO DE PESQUISAS CAFEEIRAS, 22, 1996, Águas de Lindóia. Anais... Águas de Lindóia, SP: SDR/Procafé/Embrapa, 1996, p. 99-100.

SILVEIRA, J.S.M. Irrigação em cale: café conilon irrigado no Espírito Santo. In: SIMPÓSIO ESTADUAL DO CAFÉ, 1., 1995, Vitória, ES. Anais... Vitória: Cetcaf, 1996. p. 66-83.

SRINIVASAN, C.S.; RAJU, K.S.; VISHVESHWARA, S. Pattern of fruit growth and development in interspecific hybríds of Coffea canephora x $C$. arábica. Índia Coffee, v. 42, p. 120-125, 1978.

SYLVAIN, P.G. El ciclo de crecimiento de Coffea arabica. Turrialba: Instituto Interamericano de Ciências Agrícolas, 1958. 17p. 